International Review of Research in Open and Distributed Learning Volume 17, Number 5

September $\mathbf{- 2 0 1 6}$

\title{
Exploring Communication and Course Format: Conversation Frequency and Duration, Student Motives, and Perceived Teacher Approachability for Out-of-Class Contact
}

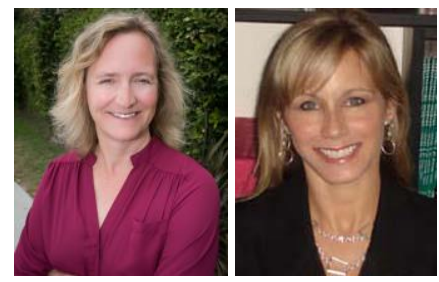

Catherine F. Brooks ${ }^{1}$ and Stacy L. Young ${ }^{2}$

1 University of Arizona, ${ }^{2}$ California State University, Long Beach

\begin{abstract}
This study explored how course instructional format (i.e., online, face-to-face, or hybrid) is related to the frequency and duration of out-of-class communication (OCC) between college instructors and students, to student motives for communicating with teachers, and to perceived teacher approachability for conversation outside of class. Though differences in frequency of and student motives for engaging in OCC were not significant, students enrolled in face-to-face courses reported significantly more ongoing/durative OCC with their instructors compared to students enrolled other course types (i.e., online or hybrid). Students in fully online courses reported instructors to seem less receptive to but also less discouraging of OCC than students in face-to-face or hybrid courses. Overall, this study offers a sense of how students who seek informal interaction with instructors beyond the classroom are faring amid the increased reliance on web-based learning environments in higher education.
\end{abstract}

Keywords: out-of-class communication (OCC), extra-class communication (ECC), computer-mediated communication, teacher approachability, hybrid education, online teaching, online learning, course format 


\section{Introduction}

Student perceptions in classrooms influence their propensity to seek out interaction with teachers beyond formal course settings, interaction that is often referred to as out-of-class communication (OCC). OCC is "student-faculty interaction [that happens] outside the traditional classroom" (Nadler \& Nadler, 200o, p. 176). The importance of such informal communication between students and teachers has been well established in previous literature (e.g., Pascarella, 1980), and has been linked to increased student retention (Tinto, 1993), persistence (Pascarella \& Terenzini, 1991), and motivation (Jaasma \& Koper, 1999). A similar line of research on extra-class-communication (ECC) (e.g., Bippus, Kearney, Plax, \& Brooks, 2003) also shows how productive informal contact outside of the formal classroom can be for students' learning experiences. As many educators and scholars interested in issues of pedagogy already know, the positive impact of informal talk between teachers and students beyond formal class instruction is profound.

The research on OCC to date, like that on ECC, has focused primarily on the traditional instructional format (i.e., face-to-face learning), but many campuses have expanded distance education efforts to include increased offerings of online or hybrid courses. With limited to no in-person communication in some types of courses, especially those formally online and involving distributed learners, teachers may have fewer (or different) strategies to connect with their students (e.g., teleconferencing, social media) compared to strategies that seem to work for on-campus instructional experiences. The nature of contemporary OCC (i.e., where and how it happens, frequency or length of contact) may have shifted away from formalized face-to-face office hours and toward online sites for OCC, for example. This study contributes to the growing conversation about communication in increasingly online learning environments or across classroom formats.

Classroom format has been measured differentially across studies (e.g., Nwabueze, 2006). Hybridized environments are those relying on face-to-face contact combined with distributed experiences (Brooks, 2010), and hybrid courses, in particular, are also often considered a blended design (Patchan, Schunn, Sieg, \& McLaughlin, 2015). Three general course formats are the focus for this project: online, hybrid, and face-to-face. With a focus on the impact of learning environment and sets of learners, this research explores how these classroom formats relate to OCC frequency and duration, students' motivations for engaging in OCC with their instructors, as well as students' perceptions of teacher approachability.

\section{Out-of-Class Communication}

Interaction outside of the classroom setting is important. It has been referenced differentially in the literature, but in general terms it refers to conversation that happens outside of the realm of course lecture, discussion, or similar formalized class talk. Early on, Pascarella (1980) wrote about "nonclassroom" contact or "students' informal contact with faculty" (p. 547), but over time Nadler and Nadler (2000) and many others (e.g., Aylor \& Oppliger, 2003; Jaasma \& Koper, 1999; Jones, 2008) began to reference "OCC contact" as involving office visits or "student-faculty interaction outside the traditional classroom” (Nadler \& Nadler, p. 176). O'Keeffe's (2013) recent work exemplifies the continued relevence of the OCC construct, arguing the importance of student-faculty relationships and the primary role played 
by those connections in successful college experiences. Some scholars examine predictors of OCC, with teacher characteristics such as credibility (Myers, 2004) or instructor rapport (Sidelinger, Bolen, McMullen, \& Nyeste, 2015), as well as student attributes like verbal aggression (Mansson, Myers, \& Martin, 2012). In addition to examining what influences OCC, scholars have pointed to a variety of positive outcomes for students who engage in OCC with their instructors (e.g., Pascarella \& Terenzini, 1991). The form of OCC has shifted somewhat over time with, most recently, studies of Facebook as an OCC tool that can be utilized to bring about positive learning outcomes (e.g., Bowman \& Akcaoglu, 2014). So, while OCC once took place in offices and on sidewalks, similar informal communication now happens via email, social media tools, or through web-based course sites designed to encourage dialogue, questions, and informal discussion of course material. Anything not scripted as part of a formal lesson plan by a teacher (though the space may be created or offered by the teacher) can be conceived as OCC.

Though the terminology is not utilized for this study, as mentioned previously, extra class communication (ECC) is a related construct used widely in the literature. The history of OCC scholarship is linked by prior research on ECC and, therefore, is considered here. When scholars talk about OCC, they often point to additional research on ECC (e.g., Kelly, Keaten, \& Finch, 2004), because both constructs similarly address teaching and learning beyond the formal class environment (i.e., online course sites, face-to-face classrooms). Fusani (1994) describes ECC as the kind of interaction that happens in such places as faculty offices or by chance on campus. Subsequent researchers (Bippus, Brooks, Plax, \& Kearney, 2001; Bippus et al., 2003) propose that ECC is a more comprehensive construct relative to the emergence of OCC, because the ECC construct includes communication within the physical classroom space but outside of the scope of formal course instruction.

... [ECC] acknowledges that informal interactions can occur within the physical classroom setting as well as in other venues. In the broadest sense, ECC includes a wide variety of informal facultystudent contact such as that which occurs before and after class, in or outside of the physical classroom setting, spontaneously on campus, during official office hours, by appointment, or via technological media such as the telephone or the Internet. (Bippus et al., 2001, p. 16)

OCC is related to ECC, historically, and the OCC-ECC connection is worth reviewing for this project given that both constructs appear in related literatures. Both OCC and ECC are constructs that encompass the important beyond-class talk students need as part of successful educational experiences. However, given this study's examination of a variety of course types, to include those that do not involve a physical classroom context per se, and given ECC's inclusion of non-class talk within physical class walls, OCC seemed the most appropriate analytic focus for this study of informal talk that may happen in courses without physically bounded space.

Overall, the consensus on OCC is positive. "Not only do students and universities benefit from studentfaculty out-of-class communication (OCC) in terms of overall retention, but also students realize benefits in the improved nature of their college experience" (Jaasma \& Koper, 1999, p. 41). Indeed, as cited previously, a long line of research in communication and education reinforces the many benefits of informal opportunities for conversation, information exchange, and instructional support for students. Though these interactions outside of the classroom are beneficial for students and universities, Jaasma and Koper (1999) show that these connections are actually quite rare for students. In addition, Jaasma 
and Koper reveal that OCC duration (conceived as length of visit) and frequency are related to in-class teacher communication behaviour (i.e., immediacy in their study). Jaasma and Koper (1999) assert that verbal immediacy is "closely linked to the frequency and length of OCC (in the office and informally)... [and] ... faculty can increase the likelihood of OCC by using language that engages students and creates rapport" (p. 45). Perceptions like this were the focus of subsequent research (Bippus et al., 2001) that revealed that students making decisions about communication with their teacher "may put inordinate emphasis on a teacher appearing to be friendly and approachable" (p. 21) instead of thinking about the use of career or course-related information the faculty member can provide. This research follows these previous studies that raise questions about communication frequency and duration, as well as the impact of teacher behaviour (e.g., approachability) on students' motivation to take advantage of OCC opportunities. Certainly many studies have examined the factors that impact students' informal communication with their teacher, and a large body of research has examined student motivation to communicate more generally (e.g., Martin, Mottet, \& Myers, 2000; Myers, Martin, \& Mottet, 2002). However, this study is unique from these other previous studies because it asks questions about these and related factors across hybrid, distance/online, and face-to-face courses - courses in which instructor behaviour may be perceived or evaluated differently by students.

\section{Primary Research Questions}

Given the importance of informal student faculty interaction for students and institutions of higher education, how these out-of-class and sometimes "chance" meetings take place in the context of increasingly web-based courses is an important site for scholarly interrogation. Across disciplines of education and communication, and in fact, across the academy, understanding the potential influence of emerging technologies on students' abilities to informally contact professors for interaction is of paramount importance. The present study intervenes in this particular area to examine relationships between classroom format and variables identified previously in OCC or ECC literature: frequency and duration of contact, student motives to seek out OCC with their professors, and perceived teacher approachability for such interactions.

Researchers (e.g., Jaasma \& Koper, 1999) have suggested the relative infrequency with which students seek out informal communication with their teachers. So, this study explores the impact of course format on OCC frequency and duration as a way to simply "take a temperature" on the evolving nature of informal faculty-student contact in differing types of courses. To do so, this first research question is posed:

RQ1: How is the instructional format of a class (face-to-face, hybrid, or online) related to the frequency and duration of out-of-class communication?

Certainly of interest for educators and researchers alike are the motives students have for seeking out communication with their professors. There are a variety of motives for seeking out communication with instructors that have been delineated in prior research (Martin, Myers, \& Mottet, 1999; Myers et al., 2002), and this study builds on that work by analysing how those motives play into students' interest in 
OCC across courses of differing format. To explore students' motives for seeking out OCC, the following question is raised:

RQ2: How is instructional format of a course (face-to-face, hybrid, or online) related to students' motives for engaging in OCC with their teachers?

Given the previous research that shows the influence of perceived teacher communication behaviourvariables such as immediacy (Jaasma \& Koper, 1999) or accessibility (Bippus et al., 2001)-this study examined the ways in which classroom format correlates with student perceptions of teacher approachability. To illuminate variability in students' perceptions of approachability across instructional format, this third and final research question addressed:

RQ3: How is instructional format related to student perceptions of their teacher's approachability?

\section{Method}

\section{Participants, Procedures, and Descriptive Information}

Four hundred ninety-five students (161 males, 333 females, and 1 declined to report) recruited from a large public southwestern university completed an online survey outside of class time regarding communication with a current professor. Modelling a procedure similar to the one originally created by Plax, Kearney, McCroskey, and Richmond (1986), participants were instructed to reflect and report on the instructor from the class they engaged with just before or immediately after the class offering this research participation opportunity. The sample consisted of freshmen $(n=238,48.1 \%)$, sophomores $(n=$ 89, 18.0\%), juniors ( $n=63,12.7 \%)$, seniors ( $n=90,18.2 \%)$, and graduate students $(n=15,3.0 \%)$. Participants ranged in age from $18-57(M=20.63, S D=4.36)$.

Following an institutional research review board's approved procedures, all student participants provided informed consent before completing their online survey. To begin the survey itself, students provided descriptive information about themselves and the class about which they were basing their responses. Not surprising, given the predominantly freshmen sample, most individuals reported on a lower division course $(n=334,67.5 \%)$ and the content taught in their class dealt primarily with the humanities and liberal arts $(n=328,66.3 \%)$. Three hundred and fourteen students $(63.4 \%)$ reported on a hybrid (half online, half face-to-face) course, with 48 (9.7\%) using a fully online course, and 133 (26.9\%) reflecting on a face-to-face only course as the basis for their responses.

To gain an understanding of the nature of their communication with their instructor, students were asked a series of questions. They reported on the primary mode of communication with their professor outside of class: email via computer, tablet, or mobile device $(n=354,71.5 \%)$, web-based courseware or discussion boards set up for the class $(n=68,13.7 \%)$, face-to-face meetings ( $n=63,12.7 \%)$, social media sites such as Facebook, Twitter, Instagram $(n=5,1.0 \%)$, text message via tablet or mobile device $(n=1$, $.2 \%)$, telephone voice calls via landline or mobile phone $(n=1, .2 \%)$, and other $(n=3, .6 \%)$. They indicated the most common location for contact with their instructor: online/mediated/not face-to-face $(n$ 
$=377,76.2 \%)$, instructor's office/face-to-face $(n=89,18.0 \%)$, not in instructor's office but on campus/face-to-face ( $n=21,4.2 \%$ ), and other ( $n=8,1.6 \%$ ). Finally, they described the back-and-forth, ongoing length, or conversational nature of their communication with their instructor, with most participants indicating a brief exchange $(n=295,59.6 \%)$, followed by no durative/back-and-forth conversations ( $n=140,28.3 \%$ ), and some lengthy conversations (e.g., more than 15 minutes of vocal talk or multiple text-based exchanges over an extended period of time) $(n=53,10.7 \%)$.

\section{Measures}

To measure students' perceptions of the frequency of their communication with their instructor, a modified version of the Young, Kelsey, \& Lancaster (2011) measure of teacher's email frequency was utilized; the measure was altered by substituting the phrase "communicate outside of class" in place of the word "email." This five-item measure employed a 5-point response Likert scale ( $1=$ strongly disagree and 5 = strongly agree), with items such as "My teacher and I communicate outside of class often" and "My teacher and I communicate outside of class regularly." Composite scores ranged from 1.00 to 5.00 $(M=$ $2.53, S D=.95, \alpha=.89$ ).

Students' views of their teacher's approachability were assessed using Bippus et al., (2001) instructor accessibility scale. This measure includes 13 items assessing perceived social accessibility (e.g., "My teacher encourages students to meet with him/her outside of class"; "My teacher is very receptive to students dropping by his/her office"). This measure used a 5-point response Likert scale (1 = strongly disagree and $5=$ strongly agree). Given the size of this measure, an exploratory factor analysis using oblimin rotation was conducted to examine its unidimensionality. To be retained in the model, items were required to have a .60 minimum for the primary loading and .40 maximum for any other loadings. Two items failed to meet these criteria ("My teacher makes it easy to ask questions before and after class" and "My teacher is very attentive to students outside of class"). The resulting model yielded two distinct factors accounting for $71 \%$ of the variance: four items composing Instructor Receptivity to OCC and 7 items for Instructor Discouragement to OCC. See Table 1. Composite scores ranged from 1.00 to 5.00 ( $M$ $=3.71, S D=.65, \alpha=.84$ ) for Instructor Receptivity and from 1.14 to 5.00 for Instructor Discouragement $(M=3.94, S D=.71, \alpha=.93)$.

Table 1

Item Loadings for Teacher Approachability Exploratory Factor Analysis

Item

My teacher seems impatient about interacting with students outside of class

My teacher doesn't seem to have time outside of class for students' concerns.

My teacher seems too rushed to deal with students outside of class.

I find it difficult to approach my teacher outside of class.

My teacher discourages student contact outside of class.

\begin{tabular}{ll} 
Instructor & Instructor \\
Discouragement & Receptivity \\
\hline
\end{tabular}

.899

.893

.875

.851

.826 
My teacher seems distant when interacting with students outside of class.

.822

My teacher gets annoyed when students try to talk to him/her outside of class or office hours.

.718

My teacher wants us to come by and visit him/her in the office.

My teacher is very receptive to students dropping by his/her office.

.912

My teacher encourages students to contact him/her outside of class.

My teacher is never too busy to talk with students outside of class.

In investigating students' motives for communicating with their instructor outside of class, a modified version of Martin et al., (1999) Student Communication Motives scale was used. This measure originally consisted of 54 items assessing five different reasons why students may communicate with their instructor outside of class, including relational motives (i.e., developing relationships), functional motives (i.e, obtaining information), excuse-making motives (i.e., to offer excuses), participation motives (i.e., to contribute questions or comments), and sycophancy motives (i.e., image management). The creators of the measure subsequently and successfully reduced the number of items on the measure to 30 (Myers et al., 2002). To attempt to further consolidate the measure in an effort to minimize participant attrition on this survey, the top three item loadings on each of the five factors reported by Martin et al., (1999) were selected for use in this project, which reduced the measure to 15 items, with three items per factor. Individuals responded to each item using a 5-point Likert-type scale, $1=$ not at all like me to $5=$ exactly like me. To ensure the stability of the proposed five factor model, all 15 items were submitted to a confirmatory factor analysis. In addition to the chi-square statistic, the non-normed fit index (NNFI), comparative fit index (CFI), and root mean square error of approximation (RMSEA) were also examined to assess model fit. Based on the CFA parameters discussed previously, the resulting CFA yielded a reasonable fit, $\chi^{2}(80)=321.219, p=.000 ; \mathrm{NNFI}=.919, \mathrm{CFI}=.937$, RMSEA $=.079$. Composite scores for each factor were as follows: Relational motive (range $=1.00-4.67, M=2.09, S D=.98, \alpha=.89$ ), functional motive (range $=1.00-5.00, M=3.79, S D=.86, \alpha=.79$ ), excuse-making motive (range $=1.00-$ 5.00, $M=2.49, S D=1.08, \alpha=.85$ ), participation motive (range = 1.00-5.00, $M=2.76, S D=.99, \alpha=.74$ ), and sycophancy motive (range $=1.00-5.00, M=1.86, S D=.85, \alpha=.83$ ).

\section{Results}

A summary of the results can be found in Table 2 below. In examining how the course format of a class (face-to-face, hybrid, or online) relates to the frequency and duration of communication (RQ 1), findings revealed no significant differences between course format on frequency of OCC, $F(488)=1.191$, ns. However, students enrolled in face-to-face classes engaged in more ongoing/durative OCC with their professors $(M=1.99, S D=.60)$ than did those in hybrid $(M=1.76, S D=.59)$ or online classes $(M=1.73$, $S D=.64), F(487)=7.493, p<.001$. 
Table 2

Summary of Results

\begin{tabular}{|c|c|c|c|c|c|c|c|}
\hline \multirow[b]{3}{*}{ Contact (RQ 1) } & \multirow[b]{2}{*}{$\underline{F(d f)}$} & \multicolumn{2}{|l|}{ Online } & \multicolumn{2}{|c|}{ Hybrid } & \multicolumn{2}{|c|}{ Face-to-Face } \\
\hline & & $M$ & $S D$ & $M$ & $S D$ & $M$ & $S D$ \\
\hline & & & & & & & \\
\hline Frequency & $1.191(488)$ & 2.72 & .92 & 2.50 & .92 & 2.55 & 1.01 \\
\hline Duration & $7.493(487)^{* *}$ & 1.73 & .64 & 1.76 & .59 & 1.99 & .60 \\
\hline \multicolumn{8}{|c|}{ Student Motives (RQ 2) } \\
\hline Relational & $2.209(490)$ & 2.14 & 1.06 & 2.02 & .94 & 2.23 & 1.04 \\
\hline Functional & $.491(492)$ & 3.78 & .80 & 3.77 & .90 & 3.85 & .80 \\
\hline Participation & $.035(486)$ & 2.72 & 1.05 & 2.76 & .99 & 2.76 & .96 \\
\hline Sycophancy & $.281(486)$ & 1.77 & .99 & 1.87 & .84 & 1.86 & .81 \\
\hline Excuse-Making & $2.884(490)^{*}$ & 2.84 & 1.12 & 2.46 & 1.06 & 2.43 & 1.09 \\
\hline \multicolumn{8}{|c|}{ Teacher Approachability (RQ 3) } \\
\hline Receptiveness & $11.652(490)^{* *}$ & 3.29 & .66 & 3.77 & .61 & 3.70 & .69 \\
\hline Discouragement & $8.518(491)^{* *}$ & $3 \cdot 54$ & .69 & 3.97 & .72 & 4.02 & .68 \\
\hline $\begin{array}{l}{ }^{*} p=.05 \\
* * 0<1001\end{array}$ & & & & & & & \\
\hline
\end{tabular}

The next research question (RQ 2) examined how the course format of a class (face-to-face, hybrid, or online) shapes students' motives for engaging in OCC with their teacher. Results revealed no significant differences between course format and relational motive, $F(490)=2.209$, ns; functional motive, $F(492)$ $=.491, n s ;$ participation motive, $F(486)=.035, n s$; and sycophancy motive, $F(486)=.281$, ns. The excuse-making motive approached significance, $F(490)=2.884, p=.05$.

The final research question (RQ 3) investigated whether the type of course format affects students' perceptions of their teacher's approachability. Results revealed that mode of instruction affects students' views of their instructor's receptiveness to OCC, $F(490)=11.652, p<.001$, and his/her discouragement of OCC, $F(491)=8.518, p<$.oo1. Students enrolled in fully online classes found their teachers to be less receptive to OCC $(M=3.29, S D=.66)$ than students in hybrid $(M=3.77, S D=.61)$ or face-to-face classes $(M=3.70, S D=.69)$. Yet, students in fully online classes also reported their instructors as being less discouraging of OCC $(M=3.54, S D=.69)$ than their hybrid $(M=3.97, S D=.72)$ and face-to-face counterparts $(M=4.02, S D=.68)$.

\section{Conclusions and Implications for Distance Education}

Because we know communication-related factors correlate with students' emotions (e.g., Brooks \& Young, 2015; Titsworth, Quinlan, \& Mazer, 2010) as well as student satisfaction and motivation (e.g., Jones, 2008) in face-to-face classrooms, this study examined an important communication variable (OCC) across course format. In this study, course format (online, hybrid, or face-to-face) did not seem to 
influence the frequency of OCC, but it did relate to the durative nature of OCC, with face-to-face designs promoting the most ongoing OCC. Students were more likely to continue to engage in OCC with their professors in their face-to-face classes than in any other instructional format. As more and more courses move online, or partially online, students may move away from maintaining ongoing contact with professors outside of class. Alternatively, students who do not wish to have face-to-face with their professors may be predisposed to enrolling in technology-based courses. Certainly OCC has been examined in a variety of contemporary learning contexts, and students have been asked directly about the kinds of asynchronous or synchronous channels they prefer for communication with their teachers (e.g., Kelly, Keaten, \& Finch, 2004). New OCC tools like Facebook have also been the focus of scholarly research (e.g., Bowman \& Akcaoglu, 2014). Alongside these studies though, this current project shows that the nature of OCC shifts as it happens across environments and for differing students. This study and others like it are important given some of the changes in higher education internationally toward an increasingly number of courses and programs online.

Although students' motives for communicating with their professors did not change depending on course instructional format, one motive did approach significance. Specifically, students in online classes were slightly more likely to engage in OCC with their professors for excuse-making than were students in hybrid or face-to-face courses. Excuses for inadequacies, late papers, or missed activities may be more prevalent in online courses given the intrinsic motivation and increased need in those courses for selfdirected learning. Future studies may need to tease out how or whether students may, in fact, miss more activities, complete more late papers than they do in face-to-face or blended courses-those in which they have to physically face instructors. These factors may indeed influence the nature of OCC across distance education experiences.

In this study, students in online classes felt their professors were less receptive to OCC, but also less discouraging of it, compared to students in hybrid and face-to-face classes. In other words, students believed that the professors in their online classes were less encouraging and inviting of OCC, but they also found them to be less impatient, rushed, and distant while engaging in OCC. The mode of communication likely shapes this perception, with online instructors having few opportunities to encourage OCC but greater flexibility in engaging in it via email, social media, or other virtual modes of talk. Online instructors may, in fact, have fewer opportunities to actually convey impatience using nonverbal cues or otherwise, even when engaging via videoconference or similar tools. At least generally, this finding squares with research suggesting similar mixed findings - that sometimes online instruction is viewed as both more favourable and less favourable at the same time (e.g., Rovai, Ponton, Derrick, \& Davis, 2006). Also, the reason for this finding may be most simply that online faculty are viewed more favourably for some things - like OCC availability - compared to their face-to-face counterparts given the lack of (or differentially available) social cues.

\section{Study Limitations}

While this study was an initial road into a series of OCC studies in contemporary classrooms, the research is limited in its broad sweep of data collection. Indeed, to explore OCC across multiple instructional 
design formats, we solicited data from a wide variety of students in varied courses all taught by differing instructors. Because each class had a different instructor and given that teacher behaviour is known for its influential relationship with OCC, the impact of classroom format is to some degree mediated or moderated by individualized teacher approaches. Future research needs to build on this starting point to ascertain the relationship between teacher behaviour and format on OCC and related outcomes. Moreover, and related to this issue with comparisons across classroom formats, are questions about teacher and student propensities that draw themselves initially to certain course formats. Instructors with a certain style of teaching or students with particular learning needs or personalities may find themselves gravitating toward different types of instructional formats that rely on computing differentially. Students and teachers may also have distinct expectations for differing types of classrooms. Both may come to distinct types of courses with certain assumptions about the nature of communication in that course type. Therefore, teacher and student style, behaviours, expectations, and related variables in relation to classroom format and OCC should be interrogated and expanded upon in subsequent related research. This and other ideas for subsequent scholarly work in this area are examined next.

\section{Directions for Future Research}

Given the importance of OCC in a variety of course types (to include distance learning environments) advances in online technology that allow for more traditional interaction to occur between teachers and students will be important to continually observe while moving forward. For example, tools such as GoTo-Meeting or Google Hangout, allow for more and increasingly flexible OCC situations to arise. Contemporary OCC for online learners can be just-in-time, when student needs or questions emerge. Interaction may be durative yet somehow less rich or rewarding for certain students in some environments, and similarly, instructor-related predictors may behave differently across platforms and tools as this current study suggests. Subsequent research should look more closely at OCC in online courses specifically in order to uncover more about the nature of teacher OCC invitations, or how students perceive their teachers' accessibility and receptivity for differing types of OCC and via particular tools. Indeed, future scholarly work needs to address how new technologies enhance and shape factors like conversational frequency and duration, student motives, and perceived teacher approachability for student-teacher interaction.

Students' motives for OCC with professors, need additional and more focused scholarly interrogation in order to actually tease out the types of talk and what kinds of information students seek (e.g., careerrelated, psycho-social, course advice) or mean to share (e.g., personal, identity-related, explanations, or excuses) across formats, conversational tools, or amid variegated instructional course designs. Most certainly we have a lot of work to do in order to truly understand how students obtain certain kinds of information and how they engage in their own identity work (e.g., excuse-making or image management) online, across cultures, and in instructional contexts. Internationally, sites for OCC will differ given varying trends for hardware, courseware and even browsers. Future studies thus ought to examine how these trends as informed by geography, culture, as well as issues of access and digital division (e.g., Yates, Kirby \& Lockley, 2015) impact instructional variables like teacher-student OCC. 
Overall, this project contemporizes scholarship on OCC by investigating the influence of course format on student-teacher outside-of-class interaction. As the landscape of instructional design continues to evolve, and given what research shows relative to students' emotion and anxieties in online situations (Brooks, 2015; Brooks \& Young, 2015), this study suggests that educators may need to continually reformulate their approach to communication outside of class and in order to aid students in shifting their perceptions of extracurricular contact, and to help them leverage all that can be accomplished virtually with their instructors. OCC remains meaningful regardless of course design, and online learning environments most certainly provide new opportunities for students and teachers to engage with one other. The key to positive evolution toward distinct and innovative course designs may lie in re-envisioning the nature of OCC and how it is best facilitated, encouraged and harnessed to bring about positive student emotion and learning outcomes in $21^{\text {st }}$ century learning experiences.

\section{References}

Aylor, B., \& Oppliger, P. (2003). Out-of-class communication and student perceptions of instructor humor orientation and socio-communicative style. Communication Education, 52(2), 122-134.

Bippus, A. M., Brooks, C. F., Plax, T. G., \& Kearney, P. (2001). Students' perceptions of part-time and tenured/tenure-track faculty: Accessibility, mentoring, and extra-class communication. Journal of the Association for Communication Administration, 3o, 13-23.

Bippus, A. M., Kearney, P., Plax, T. G., \& Brooks, C. F. (2003). Teacher access and mentoring abilities: Predicting the outcome value of extra class communication. Journal of Applied Communication Research, 31(3), 260-275. doi: 10.1080/00909880305379

Bowman, N. D., \& Akcaoglu, M. (2014). “I see smart people!”: Using Facebook to supplement cognitive and affective learning in the university mass lecture. The Internet and Higher Education, 23, 1-8.

Brooks, C. F. (2010). Toward "hybridised" faculty development for the twenty-first century: Blending online communities of practice and face-to-face meetings in instructional and professional support programmes. Innovations in Education and Teaching International, 47(3), 261-270.

Brooks, C. F. (2015). Students' perceptions and emotions relative to online assessments in college courses. In L. Liu \& D. Gibson (Sr. Eds), Research Highlights in Technology and Teacher Education 2015, and Liu, L. \& Gibson, D.C. (Eds.), Society for Information Technology \& Teacher Education Association for the Advancement of Computing in Education (AACE), Waynesville, North Carolina, USA: AACE, 167-173.

Brooks, C. F., \& Young, S. L. (2015). Emotion in online college courses: Examining the influence of perceived teacher communication behavior on students' emotional experiences. Technology, Pedagogy, and Education, 24(4), 515-527. 
Fusani, D. S. (1994). "Extra-class" communication: Frequency, immediacy, self-disclosure, and satisfaction in student-faculty interaction outside of the classroom. Journal of Applied Communication Research, 22, 232-255.

Jaasma, M. A., \& Koper, R. J. (1999). The relationship of student-faculty out-of-class communication to instructor immediacy and trust and to student motivation. Communication Education, 48(1), 4147. doi: 10.1080/03634529909379151

Jones, A. C. (2008). The effects of out-of-class support on student satisfaction and motivation to learn. Communication Education, 57(3), 373-388.

Kelly, L., Keaten, J. A., \& Finch, C. (2004). Reticent and non-reticent college students' preferred

communication channels for interacting with faculty. Communication Research Reports, 21, 197-209.

Mansson, D. H., Myers, S. A., \& Martin, M. M. (2012). Students' communicative attributes and their outof-class communication with instructors. Atlantic Journal of Communication, 20(4), 237-247.

Martin, M. M., Mottet, T. P., \& Myers, S. A. (2000). Students' motives for communicating with their instructors and affective and cognitive learning. Psychological Reports, 87(3), 830-834.

Martin, M. M., Myers, S. A., \& Mottet, T. P. (1999). Students' motives for communicating with their instructors. Communication Education, 48, 155-164.

Myers, S., Martin, M., \& Mottet, T. (2002). Students' motives for communicating with their instructors: Considering instructor socio-communicative style, student socio-communicative orientation, and student gender. Communication Education, 51(2), 121-133.

Myers, S., (2004), The relationship between perceived instructor credibility and college student in-class and out-of-class communication. Communication Reports, 17(2), 129-137.

Nadler, L. B., \& Nadler, M. K. (2000). Out of class communication between faculty and students: A faculty perspective. Communication Studies, 51(2), 176-188.

Nwabueze, K. K. (2006). Technology class format versus traditional class format in undergraduate algebra. Technology, Pedagogy and Education, 15(1), 79-93.

O'Keeffe, P. (2013). A sense of belonging: Improving student retention. College Student Journal, 47(4), 605-613.

Pascarella, E. T. (1980). Student-faculty informal contact and college outcomes. Review of Educational Research, 5O(4), 545-595. doi: 10.3102/00346543050004545

Pascarella, E., \& Terenzini, P. (1991). How college affects students: Findings and insights from twenty years of research. Jossey-Bass, San Francisco. 
Patchan, M. M., Schunn, C. D., Sieg, W., \& McLaughlin, D. (2015). The effect of blended instruction on accelerated learning. Technology, Pedagogy and Education (ahead of print), 1-18.

Plax, T. G., Kearney, P., McCroskey, J. C., \& Richmond, V. P. (1986). Power in the classroom VI: Verbal control strategies, nonverbal immediacy and affective learning. Communication Education, 35(1), 43-55.

Rovai, A. P., Ponton, M. K., Derrick, M. G., \& Davis, J. M. (2006). Student evaluation of teaching in the virtual and traditional classrooms: A comparative analysis. The Internet and Higher Education, 9(1), 23-35.

Sidelinger, R. J., Bolen, D. M., McMullen, A. L., \& Nyeste, M. C. (2015). Academic and social integration in the basic communication course: Predictors of students' out-of-class communication and academic learning. Communication Studies, 66(1), 63-84.

Tinto, V. (1993). Leaving college: Rethinking the causes and cures of student attrition (2nd ed.). Chicago: University of Chicago Press.

Titsworth, S., Quinlan, M. M., \& Mazer, J. P. (2010). Emotion in teaching and learning: Development and validation of the classroom emotions scale. Communication Education, 59(4), 431-452.

Yates, S., Kirby, J., \& Lockley, E. (2015). Digital media use: Differences and inequalities in relation to class and age. Sociological Research Online, 20(4).

Young, S., Kelsey, D., \& Lancaster, A. (2011). Predicted outcome value of e-mail communication: Factors that foster professional relational development between students and teachers. Communication Education, 6o(4), 371-388.

\section{Athabasca University}

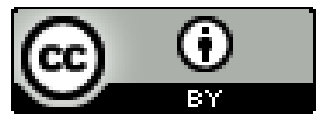

